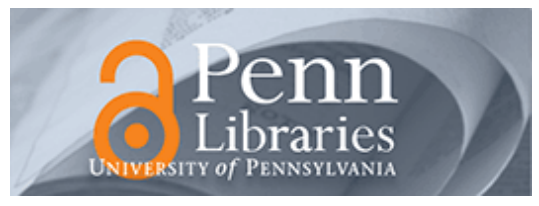

University of Pennsylvania ScholarlyCommons

\title{
Why Seeking Help From Teammates is a Blessing and a Curse: A Theory of Help Seeking and Individual Creativity in Team Contexts
}

Jennifer S. Mueller

University of Pennsylvania

Dishan Kamdar

Indian School of Business

Follow this and additional works at: https://repository.upenn.edu/mgmt_papers

Part of the Management Sciences and Quantitative Methods Commons

\section{Recommended Citation}

Mueller, J. S., \& Kamdar, D. (2011). Why Seeking Help From Teammates is a Blessing and a Curse: A Theory of Help Seeking and Individual Creativity in Team Contexts. Journal of Applied Psychology, 96 (2), 263-276. http://dx.doi.org/10.1037/a0021574 


\title{
Why Seeking Help From Teammates is a Blessing and a Curse: A Theory of Help Seeking and Individual Creativity in Team Contexts
}

\author{
Abstract \\ Research has not explored the extent to which seeking help from teammates positively relates to a \\ person's own creativity. This question is important to explore as help seeking is commonly enacted in \\ organizations and may come with reciprocation costs that may also diminish creativity. Results based on \\ 291 employees in a single division of a large multinational organization revealed that seeking help \\ predicted creativity and mediated the relationship between intrinsic motivation and creativity. However, \\ help seekers also incurred reciprocation costs in that they tended to give more help to teammates, and \\ giving help to teammates was negatively related to creativity. In general, giving higher levels of help \\ attenuated the positive relationship between help seeking and creativity. We also tested an integrated \\ model to show that help giving moderated the mediated relationship between intrinsic motivation and \\ creativity via help seeking, such that higher levels of help giving attenuated this mediated effect. We \\ discuss theoretical and practical implications recommending additional research regarding the \\ interpersonal creative process in team contexts.
}

\section{Keywords}

creativity, help seeking, help giving, intrinsic motivation

\section{Disciplines}

Management Sciences and Quantitative Methods 
Running Head: HELP SEEKING AND CREATIVITY IN TEAM CONTEXTS

\title{
Why Seeking Help from Teammates Is a Blessing and a Curse: A Theory of Help Seeking and Individual Creativity in Team Contexts
}

\author{
JENNIFER S. MUELLER \\ University of Pennsylvania \\ 3620 Locust Walk \\ Suite 3014 SHDH \\ Philadelphia PA 19104 \\ Phone: 215-898-6391 \\ Fax: 215-898-0401 \\ Email: jennm@wharton.upenn.edu \\ DISHAN KAMDAR \\ Indian School of Business \\ Gachibowli, Hyderabad 500032 India \\ Phone: 914023187192 \\ Fax: 914023007038 \\ Email: Dishan_Kamdar@isb.edu
}

Note: This research was supported by a joint initiative between the Indian School of Business and The Wharton School. We would like to thank Teresa Amabile, Sigal Barsade, Matt Cronin, Adam Grant and Katherine Klein for edifying suggestions and discussion. 


\title{
Why Seeking Help from Teammates Is a Blessing and a Curse: A Theory of Help Seeking and Individual Creativity in Team Contexts
}

\begin{abstract}
Research has not explored the extent to which seeking help from teammates positively relates to a person's own creativity. This question is important to explore as help seeking is commonly enacted in organizations and may come with reciprocation costs that may also diminish creativity. Results based on 291 employees in a single division of a large multinational organization revealed that seeking help predicted creativity and mediated the relationship between intrinsic motivation and creativity. However, help seekers also incurred reciprocation costs in that they tended to give more help to teammates, and giving help to teammates was negatively related to creativity. In general giving higher levels of help attenuated the positive relationship between help seeking and creativity. We also test an integrated model to show that help giving moderated the mediated relationship between intrinsic motivation and creativity via help seeking, such that higher levels of help giving attenuated this mediated effect. We discuss theoretical and practical implications recommending additional research regarding the interpersonal creative process in team contexts.
\end{abstract}

Keywords: creativity, help seeking, help giving, intrinsic motivation 


\section{Why Seeking Help from Teammates Is a Blessing and a Curse: A Theory of Help Seeking and Individual Creativity in Team Contexts}

Creativity, defined as the production of novel and useful ideas, fuels innovation, thereby promoting competitive advantage as well as organizational renewal (Amabile, 1988; Kanter, 1988). Ironically, however, the process of developing creative ideas necessitates that creative actors fail often (Fleming, 2001; Simonton, 1984), and embrace uncertainty about when and if they will find a creative solution (Metcalfe, 1986; Metcalfe \& Wiebe, 1987). To mitigate the failure and uncertainty that often accompanies creative problem solving, modern organizations have increasingly placed creative actors in team contexts (Cohen \& Bailey, 1997; Stevens \& Campion, 1994), structures theorized to support the ability for creative actors to seek the help they need (Amabile, 1996). Indeed, research suggests that help seeking, one person's request for resources from another, is one of the most frequently enacted creative problem solving strategies employed in group contexts (Hargadon \& Bechky, 2006). Interestingly, however, no research to date has explored how this pervasive behavior, help seeking, relates to a person's own creativity.

The creativity literature has amassed an impressive amount of evidence showing that help seeking positively relates to creativity, but has focused on help seeking as a group level process and how this process influences group level creativity. Specifically, Hargadon \& Bechky, (2006) note that groups with strong help seeking norms performed more creatively. Taggar (2002) found that group level averages of all types of different proactive behaviors enacted in teams (including, but not limited to, help seeking) related positively to group creativity. Amabile, Conti, Coon, Lazenby \& Herron (1996) showed that work groups with high levels of work group supports - an overall work environment variable which encompasses norms for help seeking tended to perform more creatively. Sutton \& Hargadon (1996) noted that help seeking often occurred during successful group brainstorming tasks. Given the pervasive evidence that help 
seeking as a group level process positively relates to group creativity, research might assume that help seeking at the individual level should also positively relate to creativity.

However, a closer examination at the literature on help seeking in addition to the theory of creativity at the individual level sheds considerable doubt on whether help seeking does indeed facilitate a person’s own creativity. Indeed, network theory and empirical research suggests that seeking help from others one interacts with frequently (as co-membership in a team structure might imply) should diminish a person's own creativity by exposing them to redundant information (Perry-Smith, 2006; Perry-Smith \& Shalley, 2003). In addition, individual level help seeking may involve interpersonal costs - seekers need to reciprocate help (Bergeron, 2007) - a cost which is not apparent when focusing on help seeking at the group level (Hackman, 2003). We propose that the interpersonal cost experienced by creative actors is important to consider because it can have negative implications for creativity. Specifically, in the current investigation, we show that help seeking incurs the price of help giving and explain why giving help during creative problem solving is particularly detrimental to one's own creative output.

In sum, the question of whether and how help seeking relates to individual level creativity is a complex one that research has not yet answered. To fill this gap we integrate the literature on help seeking, help giving, and individual level creativity to expand each. First, combining research on help seeking and creativity answers a recent call for research to expand what we know about how interpersonal relationships influence creativity at the individual level (George, 2007; Perry-Smith \& Shalley, 2003; Shalley, Zhou, \& Oldham, 2004). Currently the theory of individual level creativity tends to focus more on intra-psychic processes (e.g., cognitions, felt emotions) rather than interpersonal processes like help seeking. For example, the intrinsic motivation principle states that a person's own feelings of enjoyment and challenge promote creativity because they stimulate cognitions believed to promote creative outcomes 
(Amabile, 1996). In the current investigation we infuse the intrinsic motivation principle with an interpersonal perspective by providing theory and evidence to suggest that intrinsic motivation can propel creative actors to engage in relational activities like seeking help. Second, our integration answers a call to broaden our understanding of the ways in which intrinsic motivation relates to creativity as some research has failed to find a positive relationship (c.f. George, 2007). Our results suggest that in group contexts, help seeking behaviors partially mediate the relationship between intrinsic motivation and an individual's creativity.

Third, exploring individual-level help seeking behaviors during the creative process allows us to identify interpersonal costs which are not apparent when focusing on intra-psychic creative processes or group level help seeking. Forth, these interpersonal costs are important to explore because they may reduce creativity, a view which expands the help seeking literature which tends not to link interpersonal costs with actual performance-related outcomes. In sum, we expand the theory of individual level creativity by adapting this theory to better reflect the interpersonal costs and benefits individuals prominently encounter when creative problem solving in groups. To test our model of help seeking and creativity we employ field data from 291 employees within 55 teams, tasked with finding new and improved ways to increase efficiency and productivity in an oil refinery.

\section{Theory and Hypotheses}

Although the empirical exploration of the help seeking and creativity relationship is relatively recent, help seeking behaviors are indirectly implicated by classical theory describing the creative process. The creative process occurs when individuals gather and then use information to arrive at a creative outcome. Specifically, building upon Wallas (1926) and Nystrom (1979), Amabile (1996) identified several cognitive and behavioral activities that creative actors engage in during creative problem solving. This taxonomy includes the search for 
information related to the problem. Theory suggests that greater information-seeking efforts will yield a broader base of information which a person can then use to combine in novel and useful ways. Amabile's theory of creative cognition identifies that the thoughts and behaviors experienced by creative actors are the most proximal predictors of creative outcomes.

We focus exclusively on help seeking from teammates during creative problem solving (as opposed to help seeking broadly defined); this integrates a novel perspective into Amabile's theory of creative processes. Specifically, help seeking is a specific type of information seeking behavior (Lee, 1997). However, help seeking is particularly relevant to team contexts because seeking help is inherently interpersonal and visible, as it necessitates a request for help from another person (DePaulo \& Fisher, 1980). In contrast, information seeking and even feedback seeking, which is also a type of information seeking (VandeWalle, Ganesan, Challagalla, \& Brown, 2000), can occur without interpersonal interaction (e.g., observing a conversation, or browsing the internet). In addition, unlike information seeking and feedback seeking, both of which can theoretically occur even in the face of a seeker's successful outcome, we propose that help seeking during creative problem solving requires seekers to view the prior way of framing or thinking about the problem as flawed. This view is consistent with the help seeking literature which proposes that seeking help requires seekers to view that they are attempting to overcome difficulties or problems (DePaulo \& Fisher, 1980; Lee, 1997, 1999, 2002; Vogel \& Wester, 2003). Hence, in a feedback seeking paradigm an employee may ask for confirmation that her existing idea is correct. In contrast we focus on instances when seekers request assistance because they perceive that the prior way of solving the problem was inadequate to generate a creative solution.

A focus on help seeking from teammates during creative problem solving is important because it provides a mechanism to explain how actors might harness the creative resources 
available in the form of other teammates' perspectives and knowledge. Ironically, this is because help seeking involves seekers’ view that prior creative problem solving attempts were either unsuccessful or inadequate. Prior theory of creative processing suggests that two conditions are necessary for creativity to emerge. Greater exposure to different ideas may provide seekers with a higher likelihood of combining different ideas and creating something new, but this is only true if seekers are open to integrating the information (Amabile, 1996). In other words, mere exposure to information is necessary but insufficient to ensure a creative actor actually uses the information. This is because during creative problem solving efforts, creative actors solve problems using problem representations, mental structures that people develop to help simplify problem solving efforts (Cronin \& Weingart, 2007; Jones \& Schkade, 1995; Newell \& Simon, 1972). Cronin and Weingart suggest that problem representations can blind people from ways of thinking about the problem outside of their own representation because the representation helps guide the seeker to efficiently integrate information deemed useful and relevant to the problem. This view is consistent with research on the confirmation bias, which suggests that actors will naturally seek out information that tends to confirm the actor's existing biases and beliefs about a given problem (Nickerson, 1998; Watson, 1960). However, the theory on cognitive representations suggests that even if seekers are exposed to information outside their representation (e.g., a mathematician exposed to a concept used in biology), they will have a lower likelihood of integrating this information unless they view their current representation of the problem as flawed or incomplete.

When seeking help, seekers are more likely to approach creative problem solving with the view that they need help; the past way of representing the problem was flawed, incorrect, or has failed to generate a solution. This allows seekers greater probability of being open to new and different perspectives thereby breaking perceptual sets and performance scripts which 
dominate much of general problem solving and diminish creativity (Amabile, 1988). In addition, seeking help may cue recipients of the request to approach the problem differently than the seeker and divulge information that they expect the seeker might not know. This is because help requests are interpreted by the request recipient to imply that the prior strategy used to solve the problem was flawed or incomplete (Bohns \& Flynn, 2010; Lee, 2002), so rather than confirming the prior strategy, help request recipients are prompted to divulge different and new ways of solving the problem. This is especially important in team contexts where group pressures to divulge information common to both parties is particularly high (Stasser, Stewart, \& Wittenbaum, 1995). In this way, help seeking should aid individual creativity by allowing the individual greater likelihood of accessing as well as integrating different ideas and perspectives held by teammates.

Hypothesis 1: Seeking help from teammates during creative problem solving positively relates to individual level creativity.

The literature regarding help seeking can inform the theory describing the relationship between intrinsic motivation and creativity in team contexts. Amabile’s (1996) intrinsic motivation principle of creativity explains that intrinsic motivation will facilitate creativity because it directly increases engagement in the creative process, including search behaviors. This is because intrinsic motivation propels creative actors to feel greater curiosity, enjoyment, and challenge about a given problem (Amabile, 1996; Csikszentmihalyi, 1997). This causes creative actors to expend extra effort to engage in search behaviors as opposed to simply using the most accessible or direct pathway to the goal. In addition, because creativity is associated with a high failure rate (Fleming, 2001; Simonton, 1984), people who enjoy and feel challenged by the work will persist in light of setbacks or difficulties. Hence, intrinsically motivated actors may persist by seeking help in light of failure as opposed to less intrinsically motivated actors, who may discontinue creative problem solving efforts subsequent to failure. 
The help seeking literature has also shown that when actors seek help they face a higher likelihood that observers will view they lack competence; seeking help implies dependence on the help giver and an inability to achieve the task alone (Lee, 1997, 1999, 2002). In addition, research also shows that employees are aware of the competence costs incurred when seeking help (Hofmann, Lei, \& Grant, 2009), as certain groups of employees seek help less frequently than they might need (Lee, 1997). The feeling of enjoyment and challenge in the work may be a critical lever explaining why employees would willingly pay the perceived competence cost of seeking help. Indeed, self-determination theory suggests that, rather than simply focusing on avoiding punishment or drive reduction, people are naturally inclined towards engaging in activities that promote growth (Deci \& Ryan, 1985). Such activities can take the form of an increased interest in and exploration of a specific content domain, but may also involve a person's inclination to build a sense of belonging and relatedness with others (Ryan \& Deci, 2000). Self-determination theory would explain that, even in the face of potential costs, creative actors would still engage in creative problem solving in the form of help seeking behaviors if they felt a sense of interest and enjoyment in the work. While seeking help from teammates may be a particularly important mechanism explaining why intrinsic motivation relates to creativity in team context, we acknowledge that help seeking is not the only means through which intrinsic motivation relates to creativity (Ruscio, Whitney, \& Amabile, 1998). In sum, we integrate the intrinsic motivation principle with help seeking literature and propose that in team contexts, help seeking behaviors partially explain why intrinsic motivation relates to creativity.

Hypothesis 2: Seeking help from teammates during creative problem solving partially mediates the relationship between intrinsic motivation and individual level creativity.

\section{The Interpersonal Costs of Seeking Help}


Research and theory provide compelling evidence that seeking help increases the extent to which seekers reciprocate by giving help (Clark, Gotay, \& Mills, 1974; Cohen \& Wills, 1985; Flynn, Reagans, Amanatullah, \& Ames, 2006). Sociological research has identified that most social relations are defined by norms for reciprocity (Blau, 1964; Emerson, 1976; Gouldner, 1960). Additionally, prominent theories of relationship formation note that relationships are characterized by interdependence which involves some type of give and take (Reis, Collins, \& Berscheid, 2000; Thibaut \& Kelley, 1959). In exchange relationships most commonly found amongst peers in organizational settings (Clark \& Mills, 1993), norms for reciprocity are dictated by relatively equal exchange with appropriate delay (Fiske, 1992). Helping is an exchange resource (Cohen \& Wills, 1985; Flynn et al., 2006), so giving help comes with the expectation of some future reciprocation, unless giving help repays a past helping debt (Parris, 2003). Social exchange theory would propose that individuals will more likely give help if helping another will result in some type of payoff (Emerson, 1976). Thus, asking for help provides a person with resources but requires that askers reciprocate something - otherwise, askers risk the possibility that their help requests will remain unfilled as teammates may see little personal gain in filling them (Lee, 1997). Indeed, one study showed that helping another ensured that future help seeking attempts were fulfilled (Eisenberger, Cotterell, \& Marvel, 1987). We propose that help seekers often reciprocate by helping others on the team as this will increase their ability to gain the resources they need when sought.

Hypothesis 3: Seeking help from teammates during creative problem solving positively relates to individual level help giving during creative problem solving.

\section{How Reciprocation Costs Relate to Creative Performance}

Helping teammates is a necessary cost of seeking help, as helping allows seekers to meet basic social obligations and ensure that help seeking requests are fulfilled. However, 
reciprocation costs of helping may also contribute to performance costs as well. Evidence suggests that giving help can reduce a team-member’s own performance (Barnes, Hollenbeck, Wagner, DeRue, Nahrgang, \& Schwind, 2008), because the act of helping can diminish the amount of time and energy a person has to devote to their own tasks (Bergeron, 2007). In addition, helping diminishes the perception that one has time to achieve creative goals (Bolino \& Turnley, 2005); this may further diminish creativity as empirical evidence shows that extremely high time pressure negatively influences creativity (Amabile \& Conti, 1999; Amabile, Hadley, \& Kramer, 2002; Baer \& Oldham, 2006; Byron, Khazanchi, \& Nazarian, 2010; Mueller, Amabile, Simpson, Hadley, Kramer, \& Fleming, 2003).

One additional reason why giving help might diminish a person’s own creativity involves the way helpers approach creative problem solving during the act of helping. To reiterate, creative problem solving theory identifies the extent to which creative actors combine divergent pieces of information increases the likelihood of arriving at a novel solution. However, if activities occur in an actor's environment to reinforce a person's worldview, the person will experience less likelihood of viewing divergent information as relevant to a given problem. This view is consistent with Cronin and Weingart's (2007) idea that people are naturally resistant to changing their problem representation, and this tendency is magnified if people encounter situations that reinforce their problem representation. We propose that helping others serves to validate the helpers’ own problem representations as more accurate or better than the person whom they help. This is because the social dynamics of helping another promotes the perception that the person receiving help is less competent in the given domain than the helper and dependent upon the helper (Lee, 2002). Moreover, helping others does not require that helpers question their own problem representations or views of the problem, but instead use their existing worldview to improve upon seekers’ clearly less valid way of viewing the problem. 
Hence, while helpers are exposed to seekers’ ideas and thoughts about a given problem, helpers do not absorb seekers’ perspectives because helpers view these perspectives and solutions as inferior to their own.

In sum, we propose that a certain amount of helping is necessary to meet basic social obligations to ensure help seeking requests are fulfilled (Flynn, 2003). However, controlling for help received, helping negatively relates to a person’s own ability to perform creatively. Hence, we hypothesize the following:

Hypothesis 4: Controlling for help received, helping teammates during creative problem solving negatively relates to individual level creativity.

Resource allocation theory notes that the time and energy a person has is finite (Becker, 1965), so engaging in one behavior (like help giving) necessitates that a person has less time to engage in another behavior (like help seeking). During creative problem solving, seeking help can directly help team members gain the information or resources they need to solve a problem creatively. In contrast, giving help might indirectly aid creative problem solving by fulfilling social obligations to ensure future help seeking requests yield help receipt, but directly diminishes the time team-members have to engage in performing their own creative work (Bergeron, 2007). In addition, theory of problem representation change suggests that anything which diminishes a person’s adherence and attachment to a specific way of thinking about a problem will enhance the likelihood of integrating novel information outside of the representation. We propose that help seeking and giving each have opposite influences on adherence to a person’s problem representation - help seeking diminishes and help giving enhances adherence to preexisting ways of thinking about creative problems. Taken together, both perspectives suggest that employees may need to make tradeoffs when deciding to give and seek help. 
We have proposed that reciprocity norms enhance the likelihood that seekers will repay givers by giving help in return. However employees may decide to give help regardless of whether the helping repays past seeking attempts as research shows that helpers enjoy higher levels of social status and positive evaluations (Flynn, 2003; Flynn \& Brockner, 2003; Flynn et al., 2006). Additionally seeking help does not always necessitate repayment by giving help; theory suggests that seekers may repay helpers by emphasizing helpers’ relatively high status (Baumeister, 1982) or implicating that helping might aid helpers’ public image (Apsler, 1975; Steele, 1975). However, the decision to give high levels of help may diminish the extent to which help seeking relates to creativity. Giving help may decrease the actual amount of time seekers have to work individually. By diminishing the actual amount of time a person has to spend on their own creative work, giving help may also increase perceptions of time pressure which may result in the person finding a more direct and efficient (and less creative) way of solving the problem (Amabile et al., 2002). In addition, the extent to which seekers give help may undo the cognitive flexibility associated with less rigid cognitive representations that seekers gain when they seek help. Hence, it is possible that help seekers have more resources to give to their own creative endeavors and more flexible ways of thinking about them when they choose to give lower levels of help.

Hypothesis 5: Giving help to teammates during creative problem solving moderates the relationship between help seeking during creative problem solving and individual level creativity such that the positive relationship between help seeking and creativity decreases as the level of help giving increases.

Assuming that the extent to which a team member gives help to teammates moderates the association between help seeking and creativity, it is also likely that the level of help giving to teammates may influence the strength of the indirect relationship between intrinsic motivation 
and creativity. Figure 1 illustrates this pattern of moderated mediation between the study variables.

Insert Figure 1 about here

Because we predict that giving help to teammates will attenuate the positive relationship between help seeking and creativity, we expect the following:

Hypothesis 6: Help giving moderates the positive indirect effect of intrinsic motivation on creativity (through help seeking).

Specifically, higher levels of giving help to teammates attenuates the extent to which help seeking mediates the indirect effect of intrinsic motivation on creativity.

\section{Method}

Procedures and Participants. We collected survey data from engineers working within a single division of a large multi-national refinery in central India. The engineers within this division work within teams $(\mathrm{n}=55)$. Employees were responsible for the design and operation of measurement instruments which are used in the automated systems within the company's oil refinery. Employees were expected to manage instrumentation projects from inception to completion and were responsible for recommending improvements in the instrumentation systems. Specifically, the organization encourages employees and work groups to creatively improve operations, lower costs and increase availability of approximately 4500 instruments associated with the plant's control system. Creative restructuring of work and process flow can reduce random failure - random failure has cost the company approximately 20 million US dollars from January 2005 to January 2008. For example, a team last year was able to creatively brainstorm and problem solve to identify a bad valve which in turn was connected to 120 other valves. This solution and others have helped save the company millions of dollars. This company explicitly encouraged creativity of its employees through explicit formal statements as well as informal management practices. 
Data collection was identical for each team in the study. Specifically, participants were scheduled to take surveys with their teams at an on-site training room for 30 minutes of company time. In general, teams ranged in size from 3-6 members $(M=5.29$, s.d. $=.96)$. At each session, employees were briefed by the primary investigator ensuring the confidentiality of their responses. Supervisors were scheduled into a separate room so that no employee was in the general vicinity of his or her supervisor while completing the questionnaire. To ensure confidentiality and because we asked team supervisors to rate each employee on different dimensions, we coded the rating sheets so that employees' names were detached from the overall rating subsequent to completion. Response rates were $68 \%$ for employees, $72 \%$ for administrative fellows, and $80 \%$ for supervisors.

The current study employed questionnaire responses from three different sources. We asked employees to assess their own help seeking and giving behaviors as well as personality and motivation. We asked each team leader to rate each employee’s creativity and we asked administrative fellows (senior team members who were responsible for coaching and coordinating other members of the team) to rate each participant's social status. Our sample was comprised of 291 individuals nested in 55 unique work groups. Team leaders rated participants from a single group; hence, 55 team leaders and 55 administrative fellows rated the 291 employees. Employees were mostly male (74\%), with a mean age of approximately 32 (s.d. = 6.10) years, 5 (s.d. = 2.95) years of organizational tenure, and 70\% had a bachelors degree or higher.

Measures. With the exception of personality variables and the measure of social status, all measures involved a rating scale with anchors from 1 (strongly disagree) to 7 (strongly agree).

Self-Report Predictors: Intrinsic Motivation. We adapted a measure of intrinsic motivation based on the measure employed by Grant (2008). $(\alpha=.87)$. The intrinsic motivation 
scale asked employees to rate "why you are motivated by your work" on the following 5 items: "because I enjoy the work itself,” "because it’s fun,” "because I find the work engaging,” “because I find it challenging in a positive way,” and “because I enjoy it.”

Help Seeking Behavior. The help seeking behavior scale was based on a scale developed by Anderson and Williams (1996), and adapted to focus on asking for help from teammates regarding task related problems that required creativity to solve. Each employee rated his or her own help seeking behavior on 7 items. Sample items include: "I often approach teammates for advice when I don’t understand how to solve a problem,” “I frequently ask other teammates for assistance in creative problem solving," "I often request help from teammates when struggling to solve problems creatively," $(\alpha=.89)$.

Help Giving Behavior. Help giving behavior was measured using an 8 item scale adapted from Settoon \& Mossholder's (2002) measure of interpersonal citizenship behavior. We rewrote items to focus on giving help to teammates regarding problems that required creativity to solve - as opposed to help broadly defined. The scale included the following sample items: "I assist teammates with difficult problems solving assignments, even when assistance is not directly requested," “I go out of my way to help teammates refine their creative ideas,” "I take on extra responsibilities in order to help teammates solve problems creatively," $(\alpha=.90)$.

Dependent Variable: Creative Performance. Supervisors rated employee creativity employing a 3-item scale which research has shown to correlate with objective ratings of creativity (Oldham \& Cummings, 1996). Creativity research has commonly employed supervisory ratings of creativity (Amabile, Barsade, Mueller, \& Staw, 2005; George \& Zhou, 2001; George \& Zhou, 2002, 2007; Madjar, Oldham, \& Pratt, 2002; Zhou, 2003), as supervisory ratings are generally correlated with objective measures of creative performance (Scott \& Bruce, 1994; Tierney, Farmer, \& Graen, 1999). Supervisors who were familiar with employees’ work 
rated the creativity, originality and the practicality of the person's work. $(\alpha=.91)$. A single supervisor rated each employee.

Controls. We identified many different controls to ensure that our findings extended prior literature. We controlled for a host of demographic variables, namely: sex of subject, organizational tenure, and education, as this is generally standard in the literature. Second, we were concerned that asking for and giving help might relate to creativity primarily because they tended to co-vary with other measures identified in the creativity literature. ${ }^{1}$ We therefore controlled for the following variables:

Creative Personality. In her componential model, Amabile (1996) notes that creative relevant processing - a thinking style or personality orientation that promotes creative thinking promotes individual level creativity. We employed the creative personality scale by Gough (1979) finding that help seeking $(r=.17, p<.01)$ and help giving $(r=.22, p<.01)$ were both significantly correlated with creative personality. Hence, we controlled for the likelihood that creative personality, and not help seeking and giving, predicted creativity.

Status. To measure social status we asked one administrative fellow to rate each employee on a single item adapted from Anderson, Srivastava, Beer, Spataro \& Chatman (2006); "please rate the extent to which each person on this team has status (e.g., prestige and social standing $)$ within the team," on a 0 to 10 point scale $(0=$ none, $5=$ a moderate amount, $10=$ a great deal). Other than the inclusion of their status ratings, administrative fellows were not included as participants in the study. Research suggests that social status is highly relate to help seeking (Lee, 2002), giving (Flynn et al., 2006), and creativity (Galinsky, Magee, Gruenfeld, Whitson, \& Liljenquist, 2008), making status a very important and likely third variable.

\footnotetext{
${ }^{1}$ Running the major models without controls did not alter any findings.
} 
Help Receipt. Individuals can receive help without seeking help (Deelstra, Peeters, Schaufeli, Stroebe, Zijlstra, \& van Doornen, 2003); hence, individuals may still experience social obligations to reciprocate to others on the team without ever seeking help. To control for the possibility that reciprocity costs were incurred by help exchange behaviors other than help seeking we employed a 5 item measure of self-rated help receipt. Sample items include the following: “Teammates assist me with difficult problem solving assignments, even when assistance is not directly requested. Teammates take on extra responsibilities in order to help me solve problems creatively." $(\alpha=.91)$.

Analytic Strategy. To test our hypotheses we used multi-level modeling by employing SAS PROC MIXED which allowed us to control for group level variance and non-independence (Singer, 1998). We employed a mixed model with fixed and random effects. We included group as a random variable - which controlled for random variance at the group level to account for interdependence within nested data (Nezlek \& Zyzniewski, 1998). To reduce the correlation between slopes and intercepts in our analysis we grand mean centered all variables (Hofmann \& Gavin, 1998).

To test for mediation in a multi-level context we used the framework suggested Krull and MacKinnon (1999, 2001) who propose that the first condition for testing mediation involves showing that there is an overall effect to be mediated. The second condition involves showing that the predictor variables significantly relates to the mediator, and that the mediator relates to the criterion variable when including the predictor variable in the model. The third condition requires that the indirect effect is statistically significant in the hypothesized direction. Because our data are nested, we used a macro developed by Bauer, Preacher \& Gil (2006) to test the indirect effect of intrinsic motivation on creativity via help seeking in a multi-level context. This macro uses SAS PROC MIXED to generate a significance test of the indirect effect as well as 
95\% confidence interval of the average indirect effect. This procedure accounts for level 2 variance of the intercepts and slopes when assessing the magnitude of the indirect effect. In addition we used the approach developed by Bauer et. al. (2006) to test for moderated mediation using multi-level data, but adapted this procedure to follow the general logic of moderated mediation proposed by several scholars (Muller, Judd, \& Yzerbyt, 2005; Preacher, Rucker, \& Hayes, 2007). ${ }^{2}$ Hence, instead of exploring the extent to which the indirect effect varied across groups, we controlled for this variance using SAS PROC MIXED and focused on all variables at the individual level to assess the extent to which our indirect effect was conditional on different values of help giving.

\title{
Results
}

Table 1 shows the descriptive statistics and correlations between all major individual level variables.

\author{
Insert Table 1 about here
}

To test Hypothesis 1, asserting a positive relationship between help seeking and creativity, we ran a multi-level model controlling for random team variance well as gender, tenure, education, and creative personality, status, and help received including help seeking as our major predictor variable.

\section{Insert Table 2 about here}

Table 2, Model 3 shows a significant positive relationship between help seeking and creativity $(\gamma$ $=.62, t(228)=8.75, p<.01)$. We estimated the R-square change for the help seeking - creativity

\footnotetext{
${ }^{2}$ To our knowledge the Bauer, Preacher and Gil (2006) methodology for testing moderated mediation is the only procedure to date which accounts for the variance at level 2 when assessing the indirect effect of the independent variable on the dependent variable via the mediator for different values of the moderator. Other methods for testing moderated mediation (e.g., Edwards \& Lambert, 2007; Muller et al, 2005) do not take level 2 variance into account - and may inaccurately estimate the magnitude of the indirect effect (Bauer et al,, 2006).
} 
relationship by subtracting the total amount of variance explained by the predictor variables from the variance contained within the null model. We estimated that $26 \%$ of the variance was explained by all the variables in Table 2, Model 3. We calculated the R-square change estimating that $20 \%$ of variance was attributed to help seeking alone. Thus, we found support for hypothesis 1 .

Hypothesis 2 asserted that help seeking would mediate the relationship between intrinsic motivation and creativity. We employed a procedure suggested by Krull and MacKinnon to test for mediation when employing multi-level modeling (Krull \& MacKinnon, 2001; Preacher \& Hayes, 2004). The first step to show mediation involves regressing the criterion variable onto the predictor variable and thereby showing that there is an effect to be mediated. Table 2, Model 2 shows the multi-level model demonstrating that intrinsic motivation significantly and positively relates to creativity $(\gamma=.35, t(228)=6.18, p<.01)$ when controlling for random team variance, gender, tenure, education, creative personality, status, and help received. This result shows that there is a significant relationship between the independent variable, intrinsic motivation, and creativity; hence, the first condition is met to test for mediation.

According to Preacher and Hayes (2004) the second condition required to test for mediation involves showing that the indirect effect is statistically significant and in the predicted direction. Table 2, Model 1 shows that intrinsic motivation significantly predicts help seeking $(\gamma$ $=.32, t(228)=7.70, p<.01)$ when controlling for all major control variables as well as random team level variance. The multi-level model that includes both help seeking and intrinsic motivation when predicting creativity shows that when controlling for random team variance, tenure, gender, education, creative personality, status, and help received, help seeking remains significantly related to creativity (Table 2 , Model 4; $\gamma=.51, t(227)=6.74, p<.01$ ), and in the hypothesized positive direction. In this model intrinsic motivation is also significantly related to 
creativity (Table 2, Model 4; $\gamma=.12, t(227)=3.23, p<.05$ ), which suggests that, assuming there is a statistically significant indirect effect, help seeking may partially mediate the direct effect of intrinsic motivation on creativity (Preacher \& Hayes, 2004). A Sobel test confirmed that help seeking carries significant influence from intrinsic motivation to creativity $(z=2.86, p<.05)$. In addition, we employed a macro developed by Bauer et al. (2006) which utilizes SAS PROC MIXED to control for variance of the slopes and intercepts when calculating the simple indirect effect and a 95\% confidence interval of this effect. Specifically we identified that the simple indirect effect of intrinsic motivation on creativity through help seeking was significant and the Monte Carlo confidence interval did not overlap with zero $(\gamma=.24, \mathrm{p}<.01, \mathrm{SE}=.07$; Monte Carlo confidence interval $=.12, .41 ; \alpha=.05){ }^{3}$ Therefore, Hypothesis 2 was confirmed, showing that help seeking partially mediated the relationship between intrinsic motivation and creativity.

Hypothesis 3 asserted that help seeking would come with an interpersonal cost such that seeking help would require seekers to reciprocate by giving help in return. To test Hypothesis 3 we employed a multilevel model controlling for random team variance, gender, tenure, education, status, creative personality and help receipt showed that seeking help positively related to giving help (Table 3 , Model $1 ; \gamma=.59, t(228)=11.13, p<.01)$. Hence, Hypothesis 3 was confirmed.

\section{Insert Table 3 about here}

Hypothesis 4 asserted that reciprocation costs in the form of helping would translate to performance costs. Specifically, Hypothesis 4 stated that helping behavior negatively relates to creativity when controlling for help receipt. We employed a multilevel model controlling for random team variance, gender, tenure, education, creative personality, status, help receipt and help seeking (since help seeking is highly related to help giving and is hypothesized to have an

\footnotetext{
${ }^{3}$ To simplify our model, we employed the SAS macro developed by Bauer, Preacher and Gil (2006) without using the controls employed in Tables 2 and 3. Running analyses with and without the controls yielded identical findings.
} 
opposite relationship with creativity). Table 3, Model 2 shows that controlling for all the variables mentioned above, help giving negatively relates to creativity $(\gamma=-.29, t(226)=-3.91, p$ $<.01)$. Thus, hypothesis 4 was supported.

Hypothesis 5 asserted that the relationship between help seeking and creativity depends on the level of help giving. Specifically, the relationship between help seeking and creativity should diminish as employees engage in more help giving. The multi-level model controlling for random team variance, gender, tenure, education, creative personality, status, intrinsic motivation, and help receipt shows a significant interaction between help seeking and help giving (Table 3, Model 3; $\gamma=-.20, t(225)=-3.90, p<.01)$. The shape of this interaction is modeled on Figure 2 showing that at high (one standard deviation above the mean), mean, and low (one standard deviation below the mean) levels of help giving, the relationship between help seeking and creativity is positive but diminishing in slope.

Insert Figure 2 about here

The overall interaction term indicates that amount of change in the slope of the regression of creativity on help seeking when help giving changes by one unit is significant (Aiken \& West, 1991). Hence, all three lines are statistically different from one another, and we can confirm Hypothesis 5 and conclude that the relationship between help seeking and creativity does diminish in size as individuals engage in more help giving. We also calculated the simple intercepts and simple slopes to explore the two-way interaction using the coefficients generated from the multi-level model. We identified that at high levels of help giving (represented as one standard deviation above the mean), the simple slope for the relationship between help seeking and creativity was positive and statistically significant (Intercept $=2.95, \gamma=.56$, s.e. $=.11, t(216)$ $=5.13, p<.01)$. For the mean level of help giving, the simple slope of the relationship between help seeking and creativity was positive and statistically significant (Intercept $=3.20, \gamma=.70$, s.e. 
$=.09, t(216)=7.84, p<.01)$. For low levels of help giving (one standard deviation below the mean), the simple slope of the relationship between help seeking and creativity was the highest of the three conditions and this positive relationship was statistically significant (Intercept $=$ $3.45, \gamma=.89$, s.e. $=.10, t(216)=8.76, p<.01)$.

Hypothesis 6 depicted in Figure 1 asserted moderated mediation such that help giving would attenuate the indirect effect of intrinsic motivation on creativity through help seeking. To test the conditional indirect effect we employed a macro developed by Bauer et al. (2006) which tests the value of the indirect effect of intrinsic motivation on creativity (through help seeking) at three levels of help giving; one standard deviation above the mean $(\gamma=1.05, \mathrm{p}<.01$, $\mathrm{SE}=.20$; Monte Carlo confidence interval $=.64,1.45 ; \alpha=.05)$, mean $(\gamma=1.16, \mathrm{p}<.01, \mathrm{SE}=$ .22 ; Monte Carlo confidence interval $=.72,1.61 ; \alpha=.05)$, and one standard deviation below the mean $(\gamma=1.29, \mathrm{p}<.01, \mathrm{SE}=.25$; Monte Carlo confidence interval $=.80,1.78 ; \alpha=.05)$. The latter estimate suggests that the indirect effect of intrinsic motivation on creativity via intrinsic motivation was $10 \%$ weaker among employees who gave help at one standard deviation above the mean relative to employees who gave help at one standard deviation below the mean. Hence, Hypothesis 6 was supported.

\section{Discussion}

Our results suggest that seeking help on balance positively influences creativity. First we showed a positive relationship between help seeking and creativity and identified that help seeking partially mediated the relationship between intrinsic motivation and creativity. In addition, we added to the story of how help seeking relates to creativity by showing that help seekers incur interpersonal costs. Specifically, help seekers in our sample tended to reciprocate by helping other teammates; however, helping others was costly as helping was negatively related to creativity. Indeed, we showed that the extent to which seeking related to creativity 
depended upon the amount that seekers chose to help teammates. There was a weaker relationship between help seeking and creativity when help giving was high than when help giving was low. However, we found no evidence that the interpersonal cost incurred when help giving rendered the help seeking-creativity relationship non-significant or negative. Lastly, we tested our full model in Figure 1 to show that help giving also attenuated the indirect effect of intrinsic motivation on creativity through help seeking. In sum, we showed evidence of moderated mediation in that employees in our sample who felt intrinsically motivated achieved creative outcomes, mostly because they sought help from teammates; however, this relationship was diminished when employees gave high levels of help to teammates.

\section{Theoretical Implications}

Our study adds to the broader creativity literature by identifying the ways in which interpersonal processes predict individual creativity in groups. The perspective differs dramatically from classical theory which suggests that intrinsic motivation should relate to creativity by stimulating a person’s own creative cognition - irrespective of the person’s social interactions. Indeed, traditional creativity theory views the creative process as one which actors engage in alone - even when surrounded by others. For example, one important study explored the role of creative coworkers in enhancing a person's own creativity (Zhou, 2003). This study showed that employees with high levels of creative personality and supportive autonomy were more creative in the presence of creative co-workers. The theory explaining these results proposes that employees performed creatively because they learned by indirectly observing creative coworkers. We would propose an alternative explanation for the relationship between a person's own creativity and the presence of creative co-workers. Specifically, people may seek help from creative co-workers, who in turn may give help to employees. Future research should 
test the possibility that seeking help from the most creative co-workers may further enhance creative performance.

By broadening our understanding of the ways in which intrinsic motivation relates to creativity, we may begin to shed light on the mixed support for the intrinsic motivation creativity link (George, 2007; Grant \& Berry, Forthcoming; Shalley et al., 2004). In general, studies have found no relationship (Amabile, 1985; Dewett, 2007; Perry-Smith, 2006; Shalley \& Perry-Smith, 2001), an inconsistent relationship (Amabile, Hill, Hennessey, \& Tighe, 1994; Tierney et al., 1999) and a positive relationship (Eisenberger \& Rhoades, 2001; Shin \& Zhou, 2003) between intrinsic motivation and creativity. Our findings suggest that help seeking partially explained the indirect effect of intrinsic motivation on creativity. If help seeking partially explains why intrinsic motivation relates to creativity, then it follows that one reason why the intrinsic motivation - creativity link has yielded such mixed support may involve the extent to which actors were able to seek help in each study. In contexts where individuals were unable to seek help or sought low levels of help (e.g., laboratory tasks, individuals in work environment which discouraged help seeking), some intrinsically motivated individuals may have engaged in the types of creative processes that promoted creativity. However it is possible that many other individuals who were highly intrinsically motivated may have engaged in these creative cognitions, but came across an obstacle: their idea failed to meet an important criterion (Amabile \& Mueller, 2007), or they felt stuck (Weinstein \& Morton, 2002). In these instances, the intrinsic motivation may not relate to creativity simply because these individuals needed to seek help to overcome the obstacles they faced but could or did not.

Network theory proposes that strong ties provide an informational liability for creativity by providing actors with redundant information (Burt, 2004; Granovetter, 1973; Perry-Smith \& Shalley, 2003). However, our results show that help seeking from teammates - presumably one 
type of strong tie - positively influences creativity. This suggest that even similar others may have novel and unique ways of thinking about problem solving, so rather than an informational liability, strong ties may involve an interactional liability whereby the processes governing information exchange with similar others may inhibit the exchange of novel or unique information. Indeed, research shows that group contexts promote the sharing of common as opposed to unique information (Stasser \& Titus, 1985, 1987), and group members may choose to conform and voice similar ideas or views rather than suffer evaluation apprehension (Diehl \& Stroebe, 1987, 1991; Goncalo \& Staw, 2006). So in the absence of help seeking, seeking information from strong ties may evoke conformity pressures which promote the acquisition of redundant and commonly held information. However, help seeking may help actors overcome interactional liabilities associated with strong ties by cuing the recipients of help requests to approach the problem in a different or new way - as seekers are requesting help presumably because the past way of solving the problem was flawed. In sum, interaction processes occurring in strong tie relationships may involve processes that positively relate to creativity (e.g., help seeking) and processes which negatively relate to creativity (e.g., common information effect), which would explain why Perry-Smith (2006) found no relationship between strong ties and creativity. Future research should disentangle the extent to which help seeking may diminish the liability of strong ties for creativity.

Another contribution of the current investigation is to provide evidence that not all relationships between variables and creativity are isomorphic across levels. Some theorists have argued that the theory of creativity is homologous, in that the very factors that influence creativity at the individual level should have the same relationship to group level creativity when aggregated to the group level (Drazin, Glynn, \& Kazanjian, 1999; Gilson, 2007; Pirola-Merlo \& Mann, 2004). Past theory has identified that group level help giving is positively related to 
group level creativity (Amabile et al., 1996; Hargadon \& Bechky, 2006). However, the current study provides evidence that help giving has a negative relationship with a person’s own creativity. While homologous theories have the advantage of parsimony, they may lack predictive validity if indeed differences between levels exist (Klein \& Kozlowski, 2000). We propose that many other such differences may exist between the individual and group level factors that predict individual and group level creativity. Future research should identify key differences between the factors that influence individual and group creativity. This would allow the field to build separate yet related theories of individual and group level creativity as opposed to viewing the factors that promote each as isomorphic. From a practical perspective, if group level creativity benefits from helping norms but individuals diminish their own creativity when they help others, this suggests that organizations may face a dilemma when structuring the work environment to facilitate creativity.

\section{Limitations and Future Research}

Future research should explore other interpersonal behaviors encompassed by the creative process in team contexts. For example, research on voice - another type of proactive interpersonal behavior (Zhou \& George, 2001) - has only recently considered the performance and social repercussions of voicing creative ideas about a person's own work as opposed to improvements in the organization. Indeed, research suggests that in demographically diverse groups, individuals in the numerical minority may have more difficulty voicing creative ideas; however, when they do, group performance improves (Goncalo, Chatman, \& Duguid, 2007; Polzer, Milton, \& Swann, 2002). Additionally, idea selling may constitute another interpersonal behavior that may influence the extent to which organizations implement creative ideas (Mueller \& Melwani, 2006). 
The current theory of help seeking focuses on seeking help within a dyadic context. While we expanded this view to consider seeking help from teammates, interpersonal dynamics at the dyad level may qualify our findings. Our measure of help seeking explicitly asked participants to rate the extent to which they sought help from all or most of their teammates. In our individual data collection sessions with participants, we clarified that if participants sought help from only one teammate - this qualified as low on our measure of help seeking from most or all teammates. Even still, our measures of help seeking cannot specify the exact number of teammates an employee sought help from, nor can our measure assess the frequency of helping requests made to each teammate. We propose that the frequency or breadth of help seeking within a team should both positively relate to creativity in equal measure; help seeking reflects a cognitive shift towards greater openness to novelty, as well as a higher likelihood of cueing others (even similar others) to identify previously unconsidered options. In addition we do not expect that seeking help from a broader range of teammates will interact with the frequency of help seeking, as individuals may benefit from seeking high levels of help from one person who is extremely knowledgeable. Indeed, people tend to seek help only from those they view as most capable (Nadler, Ellis, \& Bar, 2003). However, our current methodology does not allow us to disentangle this puzzle as our goal was to take a first step towards infusing individual level creativity theory with an interpersonal perspective. As such, future research should take a more fine-grained dyadic approach to studying the dynamics of help seeking during creative problem solving in team contexts.

Our use of cross-sectional field data does not allow us to make assessments of causality or directionality. For example, it is possible that creative people generally tend to ask for help, and less creative people tend to give help. To help account for this possibility we controlled for creative personality, but creative personality did not diminish the relationship between help 
seeking, giving and creative outcomes in our study. At face value, one would expect uncreative individuals to seek more and give less help simply because people who fail to perform creatively would need more resources and have fewer to give. In addition, members who have achieved creative competence would be expected to give more help because team-members are likely to approach them for help. Our findings run contrary to these face valid associations, lending greater plausibility to the likelihood that help seeking behaviors facilitate creativity while help giving behaviors diminished creativity and not vice versa.

Another important limitation is our use of perceptual outcome measures. This limits our ability to claim whether we are truly capturing more objective indicators of creativity. Although the use of supervisory assessments of individual creativity are often employed in the creativity literature (c.f., George \& Zhou, 2001), it is possible that the positive relationship with help seeking is explained by matching employees' behaviors against a prototype of a creative person and not actual performance (Sternberg, 1985). There are three main reasons why we do not think this limitation was problematic for the current sample. First, help seeking differs from simply asking questions out of curiosity because help seeking is fueled by uncertainty or inability to solve a problem creatively. Specifically, the help seeking questionnaire we used in the current study included items like: “I often approach teammates for advice when I don’t understand how to solve a problem,” and "I often request help from teammates when struggling to solve problems creatively.” Consistent with the help seeking definition, our scale focused on instances when seekers are unable to solve a problem creatively on their own. Theory would suggest that the inability to achieve creative solutions is unlikely to be seen as matching a prototype of the creative person (Elsbach \& Kramer, 2003). Second, we have evidence that help giving diminished creativity. Surely, giving help on creative problems would match the prototype of a creative person - yet we do not find this unqualified association. Third, in the current 
organization, employee promotions and awards for creative performance were calculated based on supervisory ratings. Although we were not able to capture the supervisors' actual ratings that were given to HR, we did ask supervisors to reference their past employee ratings when making creativity assessments for the current study. Hence, supervisory ratings for our sample were likely very correlated with important objective outcomes like raises or promotions received by subordinates.

\section{Conclusions}

Help seeking from teammates is a blessing and only somewhat of a curse. While seeking help from teammates can result in improved creative performance, it also incurs the need to reciprocate help which diminishes creative performance and attenuates the positive relationship between help seeking and creativity. As we showed that help seeking was the mechanism that partially explained the relationship between intrinsic motivation and creativity, organizations would benefit from learning how to attenuate the interpersonal and related performance costs associated with seeking help. Indeed, some organizations have formalized help seeking by assigning formal roles to diminish these costs. In sum, by identifying the important role help seeking plays and the costs it incurs we can take a first step in understanding how to diminish the burden felt by employees who are the engine of creative problem solving in organizations. 
Table 1.

Descriptive Statistics For All Major Individual Level Variables, $N=291$.

$\begin{array}{lllllllllll}\text { Mean } & \text { SD } & 1 & 2 & 3 & 4 & 5 & 6 & 7 & 8 & 9\end{array}$

\section{Control Variables}

\begin{tabular}{|c|c|c|c|c|c|c|c|c|c|c|c|}
\hline 1. Gender: 0 = female, 1 = male & .74 & .44 & & & & & & & & & \\
\hline 2. Organizational Tenure & 5.00 & 2.95 & .02 & & & & & & & & \\
\hline 3. Education & 1.97 & .76 & .01 & $.21^{* *}$ & & & & & & & \\
\hline 4. Creative Personality & 5.52 & 3.44 & .07 & -.04 & .00 & & & & & & \\
\hline 5. Help Receipt & 4.48 & 1.43 & .02 & -.04 & -.05 & .12 & & & & & \\
\hline 6. Status & 5.63 & 2.45 & -.08 & .08 & $.12 *$ & .03 & .03 & & & & \\
\hline \multicolumn{12}{|l|}{ Predictor Variables } \\
\hline 7. Intrinsic Motivation & 4.51 & 1.62 & -.02 & -.09 & -.05 & $.17 * *$ & $.42 * *$ & .02 & & & \\
\hline 8. Seeking Help & 5.12 & 1.18 & .05 & -.08 & -.03 & $.17 * *$ & $.29 * *$ & $-.20 * *$ & $.48^{* *}$ & & \\
\hline \multicolumn{12}{|l|}{ Dependent Variable } \\
\hline 10. Creativity & 3.79 & 1.43 & .01 & $-.12^{*}$ & -.06 & $.11+$ & .09 & $-.24 * *$ & $.35 * *$ & $.51^{* *}$ & .04 \\
\hline
\end{tabular}

Note. $+<.10 ;{ }^{*} \mathrm{p}<.05 ;{ }^{* *} \mathrm{p}<.01$ 
Table 2.

Multi-level Models Identifying That Help Seeking Partially Mediates the Relationship Between Intrinsic Motivation and Creativity

\begin{tabular}{|c|c|c|c|c|}
\hline & Help Seeking & Creativity & Creativity & Creativity \\
\hline & M1 & M2 & M3 & M4 \\
\hline \multicolumn{5}{|l|}{ Control Variables } \\
\hline Gender: $0=$ female, $1=$ male & $.11(.13)$ & $-.02(.19)$ & $-.11(.18)$ & $-.06(.18)$ \\
\hline Organizational Tenure & $-.01(.02)$ & $-.03(.03)$ & $-.04(.03)$ & $-.03(.03)$ \\
\hline Education & $.03(.08)$ & $.01(.11)$ & $-.02(.10)$ & $-.02(.10)$ \\
\hline Creative Personality & $.02(.02)$ & $.02(.02)$ & $.02(.02)$ & $.01(.02)$ \\
\hline Help Receipt & $.09+(.05)$ & $-.07(.06)$ & $-.05(.06)$ & $-.11 *(.06)$ \\
\hline Status & $-.10 * *(.03)$ & $-.15^{* *}(.03)$ & $-.09 * *(.03)$ & $-.10 *(.03)$ \\
\hline \multicolumn{5}{|l|}{ Mediator } \\
\hline \multicolumn{5}{|l|}{ Predictor Variable } \\
\hline Help Seeking & & & $.62 * *(.07)$ & $.51 *(.08)$ \\
\hline R-square & .27 & .18 & .26 & .29 \\
\hline R-square change & .15 & .11 & .20 & .11 \\
\hline
\end{tabular}

${ }^{1}$ Unstandardized coefficients are reported; standard errors are in parentheses.

Two-tailed tests ( $\mathrm{n}=291$ at individual level; $\mathrm{n}=55$ at group level)

$+<.10$

$* \mathrm{p}<.05$

$* * \mathrm{p}<.01$ 
Table 3.

Multi-level Models Exploring The Costs and Benefits of Seeking Help

\begin{tabular}{|c|c|c|c|}
\hline & $\begin{array}{c}\text { Help Giving } \\
\text { M1 }\end{array}$ & $\begin{array}{c}\text { Creativity } \\
\text { M2 }\end{array}$ & $\begin{array}{c}\text { Creativity } \\
\text { M3 } \\
\end{array}$ \\
\hline \multicolumn{4}{|l|}{ Control Variables } \\
\hline Gender: $0=\mathrm{f}, 1=\mathrm{m}$ & $-.16(.13)$ & $-.12(.17)$ & $-.10(.17)$ \\
\hline Organizational Tenure & $-.01(.02)$ & $-.04(.03)$ & $-.04(.03)$ \\
\hline Education & $.15+(.08)$ & $.02(.11)$ & $-.00(.10)$ \\
\hline Creative Personality & $.03+(.02)$ & $.02(.02)$ & $.01(.02)$ \\
\hline Help Receipt & $.24 * *(.05)$ & $-.05(.06)$ & $-.09(.06)$ \\
\hline Status & $.25^{* *}(.03)$ & $-.03(.04)$ & $-.03(.04)$ \\
\hline \multicolumn{4}{|l|}{ Predictor Variables } \\
\hline Intrinsic Motivation & $.00(.04)$ & $.19 *(.06)$ & $.12 *(.06)$ \\
\hline Help Seeking & $.59 * *(.06)$ & $.69 * *(.09)$ & $.68 * *(.08)$ \\
\hline Help Giving & & $-.29 *(.08)$ & $-.25 *(.08)$ \\
\hline Help Seeking*Giving & & & $-.20 * *(.05)$ \\
\hline R-square & .38 & .32 & .35 \\
\hline R-square change & .27 & .03 & .03 \\
\hline
\end{tabular}

${ }^{1}$ Unstandardized coefficients are reported; standard errors are in parentheses.

Two-tailed tests ( $\mathrm{n}=291$ at individual level; $\mathrm{n}=55$ at group level)

$+<.10$

$* \mathrm{p}<.05$

$* * \mathrm{p}<.01$ 
Figure 1.

Model of Help Seeking and Individual Creativity In Team Contexts

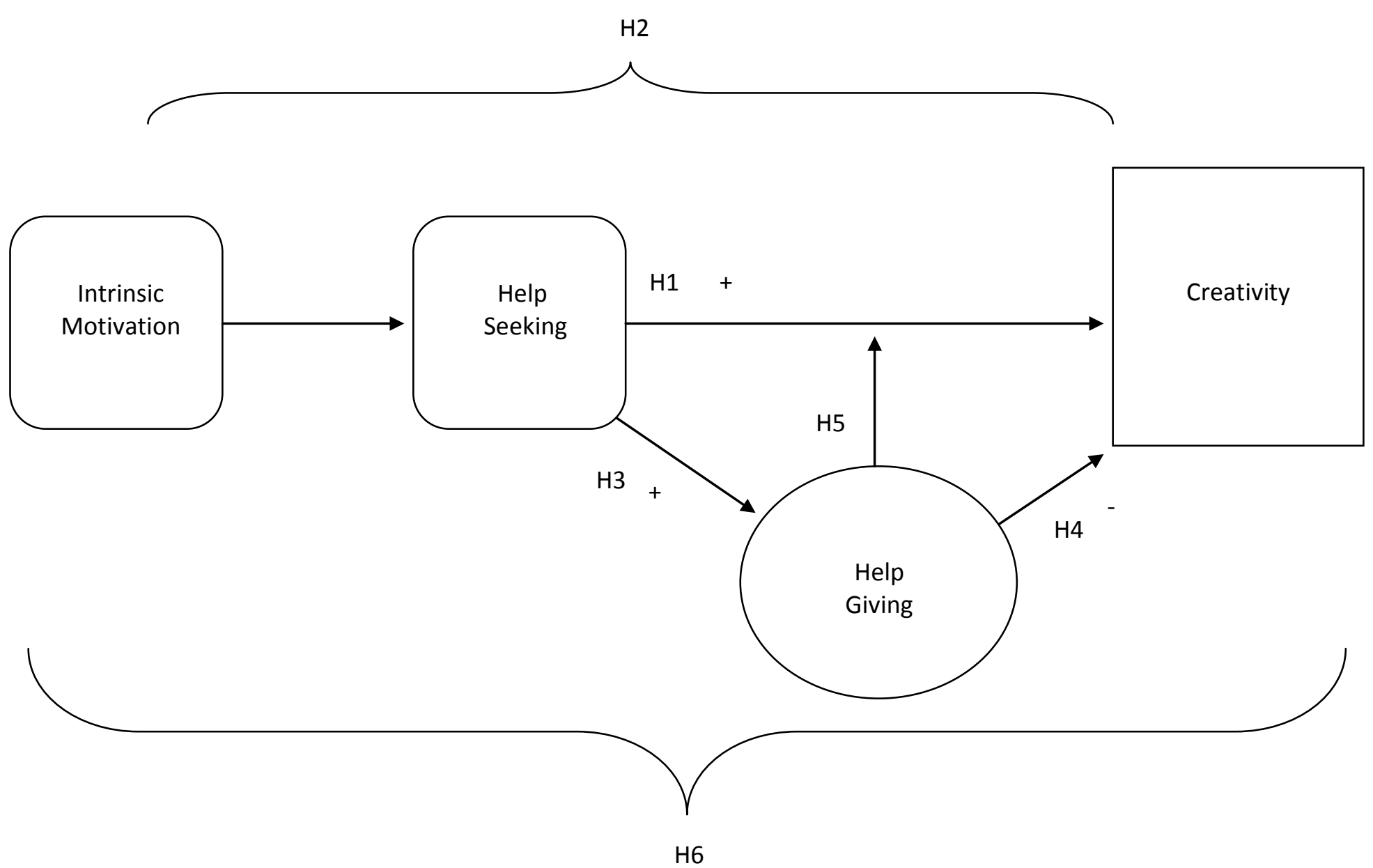




\section{Figure 2.}

Interaction Between Help Seeking and Help Giving Predicting Creativity

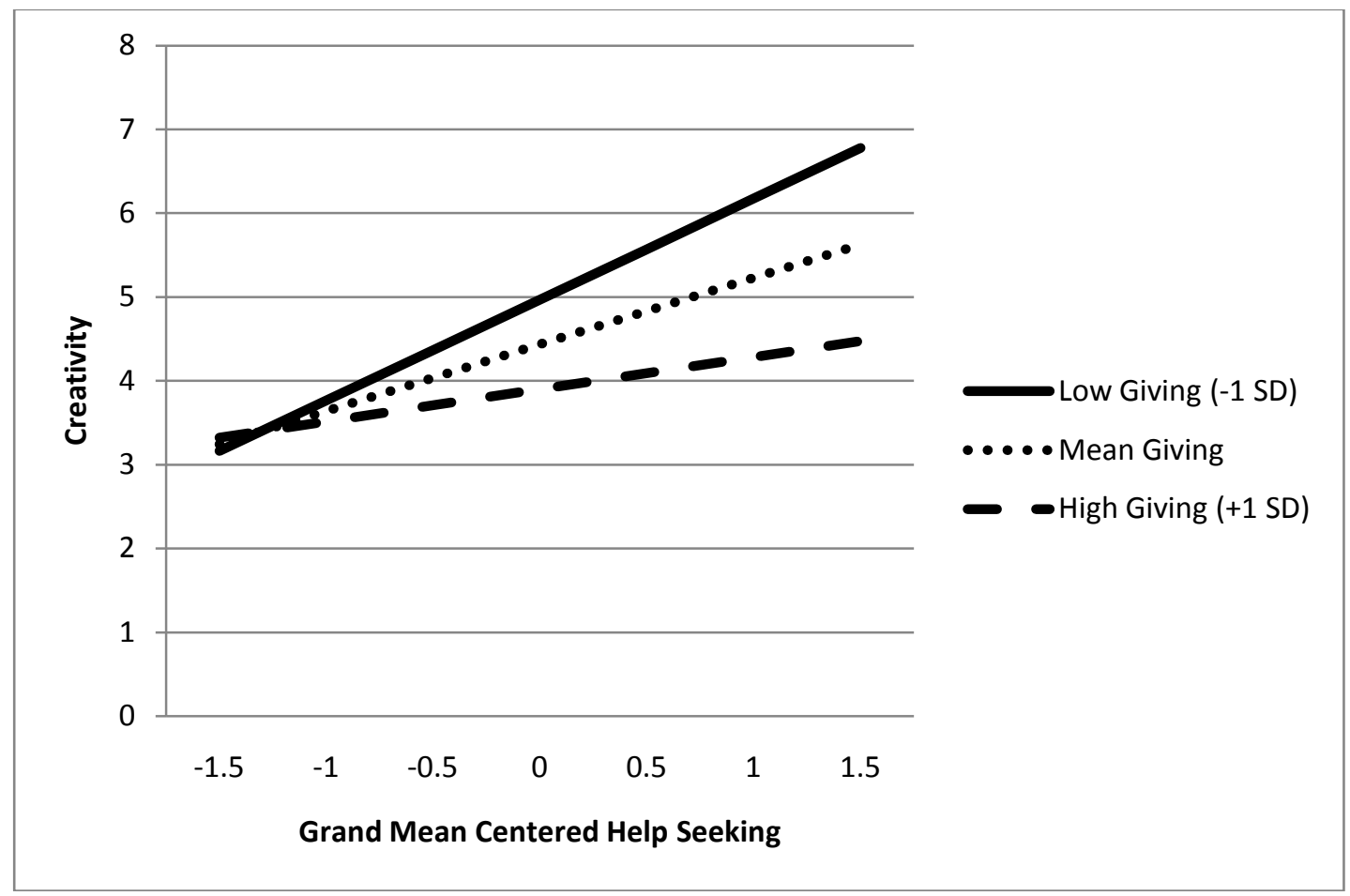




\section{References}

Aiken, L. S., \& West, S. G. 1991. Multiple Regression: Testing and Interpreting Interactions. Newbury Park, CA: Sage Publications.

Amabile, T. 1988. A model of creativity and innovation in organizations. In B. K. Staw, R. (Ed.), Research in Organization Behavior, Vol. 10: 123-167. Greenwich, CT: JAI Press.

Amabile, T., Conti, R., Coon, H., Lazenby, J., \& Herron, M. 1996. Assessing the work environment for creativity. Academy of Management Journal, 39(5): 1154-1184.

Amabile, T. M. 1985. Motivation and creativity: Effects of motivational orientation on creative writers. Journal of Personality and Social Psychology, 48(2): 393-397.

Amabile, T. M. 1996. Creativity in context: Update to "The Social Psychology of Creativity.". Boulder, CO, US: Westview Press.

Amabile, T. M., Barsade, S. G., Mueller, J. S., \& Staw, B. M. 2005. Affect and creativity at work. Administrative Science Quarterly, 50: 367-403.

Amabile, T. M., \& Conti, R. 1999. Changes in the Work Environment for Creativity during Downsizing. Academy of Management Journal, 42(6): 630-640.

Amabile, T. M., Hadley, C. N., \& Kramer, S. J. 2002. Creativity Under the Gun. Harvard Business Review, 80(8): 52-61.

Amabile, T. M., Hill, K. G., Hennessey, B. A., \& Tighe, E. M. 1994. The Work Preference Inventory: Assessing intrinsic and extrinsic motivational orientations. Journal of Personality and Social Psychology, 66(5): 950-967.

Amabile, T. M., \& Mueller, J. S. 2007. Studying creativity, its processes, and its antecedents: An exploration of the componential theory of creativity. In J. Z. a. C. Shalley (Ed.), Handbook of Organizational Creativity. Mahwah, NJ: Lawrence Erlbaum Associates. 
Anderson, C., Srivastava, S., Beer, J. S., Spataro, S. E., \& Chatman, J. A. 2006. Knowing Your Place: Self-Perceptions of Status in Face-to-Face Groups. Journal of Personality and Social Psychology, 91(6): 1094-1110.

Anderson, S. E., \& Williams, L. J. 1996. Interpersonal, job, and individual factors related to helping processes at work. Journal of Applied Psychology, 81(3): 282-296.

Apsler, R. 1975. Effects of embarrassment on behavior toward others. Journal of Personality and Social Psychology, 32: 145-153.

Baer, M., \& Oldham, G. R. 2006. The Curvilinear Relation Between Experienced Creative Time Pressure and Creativity: Moderating Effects of Openness to Experience and Support for Creativity. Journal of Applied Psychology, 91(4): 963-970.

Barnes, C. M., Hollenbeck, J. R., Wagner, D. T., DeRue, D. S., Nahrgang, J. D., \& Schwind, K. M. 2008. Harmful help: The costs of backing-up behavior in teams. Journal of Applied Psychology, 93(3): 529-539.

Bauer, D. J., Preacher, K. J., \& Gil, K. M. 2006. Conceptualizing and Testing Random Indirect Effects and Moderated Mediation in Multilevel Models: New Procedures and Recommendations. Psychological Methods, 11(2): 142-163.

Baumeister, R. F. 1982. A self-presentational view of social phenomena. Psychological Bulletin, 91(1): 3-26.

Becker, G. S. 1965. A theory of the allocation of time. Economic Journal, 75: 493-517.

Bergeron, D. M. 2007. The potential paradox of organizational citizenship behavior: Good citizens at what cost? Academy of Management Review, 32(4): 1078-1095.

Blau, P. M. 1964. Exchange and power in social life. NY, NY: Wiley.

Bohns, V. K., \& Flynn, F. J. 2010. Why didn't you just ask? Underestimating the discomfort of help-seeking. Journal of Experimental Social Psychology. Jan, 4(2010). 
Bolino, M. C., \& Turnley, W. H. 2005. The Personal Costs of Citizenship Behavior: The Relationship Between Individual Initiative and Role Overload, Job Stress, and WorkFamily Conflict. Journal of Applied Psychology, 90(4): 740-748.

Burt, R. 2004. Structural holes and good ideas. American Journal of Sociology, 110(2): 349399.

Byron, K., Khazanchi, S., \& Nazarian, D. 2010. The relationship between stressors and creativity: A meta-analysis examining competing theoretical models. Journal of Applied Psychology, 95(1): 201-212.

Clark, M. S., Gotay, C. C., \& Mills, J. 1974. Acceptance of help as a function of similarity of the potential helper and opportunity to repay. Journal of Applied Social Psychology, 4(3): 224-229.

Clark, M. S., \& Mills, J. 1993. The difference between communal and exchange relationships: What it is and is not. Personality and Social Psychology Bulletin, 19(6): 684-691.

Cohen, S., \& Wills, T. A. 1985. Stress, social support, and the buffering hypothesis. Psychological Bulletin, 98(2): 310-357.

Cohen, S. G., \& Bailey, D. E. 1997. What makes teams work: Group effectiveness research from the shop floor to the executive suite. Journal of Management, 23(3): 239-290.

Cronin, M. A., \& Weingart, L. R. 2007. Representational gaps, information processing, and conflict in functionally diverse teams. Academy of Management Review, 32(3): 761-773.

Csikszentmihalyi, M. 1997. Creativity: Flow and the psychology of discovery and invention. New York, NY, US: HarperCollins Publishers, 456.

Deci, E. L., \& Ryan, R. M. 1985. Intrinsic motivation and self-determination in human behavior. New York: Plenum. 
Deelstra, J. T., Peeters, M. C. W., Schaufeli, W. B., Stroebe, W., Zijlstra, F. R. H., \& van Doornen, L. P. 2003. Receiving instrumental support at work: When help is not welcome. Journal of Applied Psychology, 88(2): 324-331.

DePaulo, B. M., \& Fisher, J. D. 1980. The costs of asking for help. Basic and Applied Social Psychology, 1(1): 23-35.

Dewett, T. 2007. Linking intrinsic motivation, risk taking, and employee creativity in an R\&D environment. R\&D Management, 37(3): 197-208.

Diehl, M., \& Stroebe, W. 1987. Productivity loss in brainstorming groups: Toward the solution of a riddle. Journal of Personality and Social Psychology, 53(3): 497-509.

Diehl, M., \& Stroebe, W. 1991. Productivity loss in idea-generating groups: Tracking down the blocking effect. Journal of Personality and Social Psychology, 61(3): 392-403.

Drazin, R., Glynn, M. A., \& Kazanjian, R. K. 1999. Multilevel theorizing about creativity in organizations: A sensemaking perspective. Academy of Management Review, 24(2): 286-307.

Edwards, J., \& Lambert, L. 2007. Methods for integrating moderation and mediation: A general analytical framework using moderated path analysis. Psychological Methods, 12(1): 122.

Eisenberger, R., Cotterell, N., \& Marvel, J. 1987. Reciprocation ideology. Journal of Personality and Social Psychology, 53(4): 743-750.

Eisenberger, R., \& Rhoades, L. 2001. Incremental effects of reward on creativity. Journal of Personality and Social Psychology, 81(4): 728-741.

Elsbach, K. D., \& Kramer, R. M. 2003. Assessing Creativity in Hollywood Pitch Meetings: Evidence for a Dual-Process Model of Creativity Judgments. Academy of Management Journal, 46(3): 283-301. 
Emerson, R. M. 1976. Social exchange theory. Annual Review of Sociology, 2: 335-362.

Fiske, A. P. 1992. The four elementary forms of sociality: Framework for a unified theory of social relations. Psychological Review, 99(4): 689-723.

Fleming, L. 2001. Recombinant uncertainty in technological search. Management Science. Special Issue: Design and development, 47(1): 117-132.

Flynn, F. J. 2003. How Much Should I Give and How Often? The Effects of Generosity and Frequency or Favor Exchange on Social Status and Productivity. Academy of Management Journal, 46(5): 539-553.

Flynn, F. J., \& Brockner, J. 2003. It's Different to Give Than to Receive: Predictors of Givers' and Receivers' Reactions to Favor Exchange. Journal of Applied Psychology, 88(6): 1034-1045.

Flynn, F. J., Reagans, R. E., Amanatullah, E. T., \& Ames, D. R. 2006. Helping One's Way to the Top: Self-Monitors Achieve Status by Helping Others and Knowing Who Helps Whom. Journal of Personality and Social Psychology, 91(6): 1123-1137.

Galinsky, A. D., Magee, J. C., Gruenfeld, D. H., Whitson, J. A., \& Liljenquist, K. A. 2008. Power reduces the press of the situation: Implications for creativity, conformity, and dissonance. Journal of Personality and Social Psychology, 95(6): 1450-1466.

George, J. M. 2007. Chapter 9: Creativity in Organizations. The Academy of Management Annals, 1(1): 439 - 477.

George, J. M., \& Zhou, J. 2001. When Openness to Experience and Conscientiousness Are Related to Creative Behavior: An International Approach. Journal of Applied Psychology, 86(3): 513-524. 
George, J. M., \& Zhou, J. 2002. Understanding when bad moods foster creativity and good ones don't: The role of context and clarity of feelings. Journal of Applied Psychology, 87(4): 687-697.

George, J. M., \& Zhou, J. 2007. Dual tuning in a supportive context: Joint contributions of positive mood, negative mood, and supervisory behaviors to employee creativity. Academy of Management Journal, 50(3): 605-622.

Gilson, L. L. 2007. Why be creative: A review of the practical outcomes associated with creativity at the individual, group, and organizational levels. In C. Shalley;, \& J. Zhou (Eds.), Handbook of Organizational Creativity: 303-322: Lawrence Erlbaum Associates, Inc. .

Goncalo, J. A., Chatman, J. A., \& Duguid, M. M. 2007. Political Correctness and Creativity in Demographically Homogenous and Heterogeneous Groups. Paper presented the Academy of Management Meetings, Philadelphia, PA.

Goncalo, J. A., \& Staw, B. M. 2006. Individualism-collectivism and group creativity. Organizational Behavior and Human Decision Processes, 100(1): 96-109.

Gough, H. G. 1979. A creative personality scale for the Adjective Check List. Journal of Personality and Social Psychology, 37(8): 1398-1405.

Gouldner, A. W. 1960. The norm of reciprocity: A preliminary statement. American Sociological Review, 25(161-178).

Granovetter, M. 1973. The Strength of Weak Ties. American Journal of Sociology, 78: 13601380.

Grant, A. M. 2008. Does intrinsic motivation fuel the prosocial fire? Motivational synergy in predicting persistence, performance, and productivity. Journal of Applied Psychology, 93(1): 48-58. 
Grant, A. M., \& Berry, J. Forthcoming. The Necessity of Others is the Mother of Invention: Intrinsic and Prosocial Motivations, Perspective-Taking, and Creativity. Academy of Management Journal.

Hackman, J. R. 2003. Learning more by crossing levels: Evidence from airplanes, hospitals, and orchestras. Journal of Organizational Behavior, 24(8): 905-922.

Hargadon, A. B., \& Bechky, B. A. 2006. When collections of creatives become a creative collectives: A field study of problem solving at work. Organization Science, 17(4): 484500.

Hofmann, D. A., \& Gavin, M. B. 1998. Centering decisions in hierarchical linear models: Implications for research in organizations. Journal of Management, 24(5): 623-641.

Hofmann, D. A., Lei, Z., \& Grant, A. M. 2009. Seeking help in the shadow of doubt: The sensemaking processes underlying how nurses decide whom to ask for advice. Journal of Applied Psychology, 94(5): 1261-1274.

Jones, D., \& Schkade, D. 1995. Choosing and translating between problem representations. Organizational Behavior and Human Decision Processes, 61(2): 214-223.

Kanter, R. M. 1988. When a thousand flowers bloom: Structural, collective, and social conditions for innovation in organizations. In B. Staw, \& L. L. Cummings (Eds.), Research in Organizational Behavior, Vol. 10: 169-211. Greenwich, CT: JAI Press.

Klein, K. J., \& Kozlowski, S. W. J. 2000. From Micro to Meso: Critical Steps in Conceptualizing and Conducting Multilevel Research. Organizational Research Methods,, 3(3): 211-236.

Krull, J. L., \& MacKinnon, D. P. 1999. Multilevel mediation modeling in group-based intervention studies. Evaluation Review, 23(4): 418-444. 
Krull, J. L., \& MacKinnon, D. P. 2001. Multilevel modeling of individual and group level mediated effects. Multivariate Behavioral Research. Special Issue: Multilevel models, 36(2): 249-277.

Lee, F. 1997. When the going gets tough, do the tough ask for help? Help seeking and power motivation in organizations. Organizational Behavior and Human Decision Processes, 72(3): 336-363.

Lee, F. 1999. Verbal strategies for seeking help in organizations. Journal of Applied Social Psychology, 29(7): 1472-1496.

Lee, F. 2002. The social costs of seeking help. Journal of Applied Behavioral Science, 38(1): 17-35.

Madjar, N., Oldham, G. R., \& Pratt, M. G. 2002. There's no place like home? The contributions of work and nonwork creativity support to employees' creative performance. Academy of Management Journal, 45(4): 757-767.

Metcalfe, J. 1986. Premonitions of insight predict impending error. Journal of Experimental Psychology: Learning, Memory, and Cognition, 12(4): 623-634.

Metcalfe, J., \& Wiebe, D. 1987. Intuition in insight and noninsight problem solving. Memory \& Cognition, 15(3): 238-246.

Mueller, J., \& Melwani, S. 2006. The Role that Relationships Play in the Advancement of Creative Ideas in Organizational Contexts. . Paper presented at the Academy of Management, Atlanta, GA.

Mueller, J. S., Amabile, T. M., Simpson, W. B., Hadley, C. N., Kramer, S. J., \& Fleming, L. 2003. The Influence of Time Pressure on Creativity in Organizations. Paper presented at the Academy of Management Conference, Denver, CO. 
Muller, D., Judd, C. M., \& Yzerbyt, V. Y. 2005. When moderation is mediated and mediation is moderated. Journal of Personality and Social Psychology, 89(6): 852-863.

Nadler, A., Ellis, S., \& Bar, I. 2003. To seek or not to seek: The relationship between help seeking and job performance evaluations as moderated by task-relevant expertise. Journal of Applied Social Psychology, 33(1): 91-109.

Newell, A., \& Simon, H. A. 1972. Human problem solving. Oxford, England: Prentice Hall, 920.

Nezlek, J. B., \& Zyzniewski, L. E. 1998. Using hierarchical linear modeling to analyze grouped data. Group Dynamics: Theory, Research, and Practice. Special Issue: Research methods, 2(4): 313-320.

Nickerson, R. S. 1998. Confirmation bias: A ubiquitous phenomenon in many guises. Review of General Psychology, 2(175-220).

Nystrom, H. 1979. Creativity and Innovation. London: Wiley.

Oldham, G. R., \& Cummings, A. 1996. Employee creativity: Personal and contextual factors at work. Academy of Management Journal, 39(3): 607-634.

Parris, M. A. 2003. Work teams: Perceptions of a ready-made support system? Employee Responsibilities and Rights Journal, 15(2): 71-83.

Perry-Smith, J. E. 2006. Social Yet Creative: The role of social relationships in facilitating individual creativity. Academy of Management Journal, 49(1): 85-101.

Perry-Smith, J. E., \& Shalley, C. E. 2003. The social side of creativity: A static and dynamic social network perspective. Academy of Management Review, 28(1): 89-106.

Pirola-Merlo, A., \& Mann, L. 2004. The relationship between individual creativity and team creativity: Aggregating across people and time. Journal of Organizational Behavior, 25(2): 235-257. 
Polzer, J. T., Milton, L. P., \& Swann, W. B., Jr. 2002. Capitalizing on diversity: Interpersonal congruence in small work groups. Administrative Science Quarterly, 47(2): 296-324.

Preacher, K. J., \& Hayes, A. F. 2004. SPSS and SAS procedures for estimating indirect effects in simple mediation models. Behavior Research Methods, Instruments \& Computers. Special Issue: Web-based archive of norms, stimuli, and data: Part 2, 36(4): 717-731.

Preacher, K. J., Rucker, D. D., \& Hayes, A. F. 2007. Addressing moderated mediation hypotheses: Theory, methods, and prescriptions. Multivariate Behavioral Research, 42(1): 185-227.

Reis, H. T., Collins, W. A., \& Berscheid, E. 2000. The relationship context of human behavior and development. Psychological Bulletin. Special Issue: Psychology in the 21st Century, 126(6): 844-872.

Ruscio, J., Whitney, D. M., \& Amabile, T. M. 1998. Looking inside the fishbowl of creativity: Verbal and behavioral predictors of creative performance. Creativity Research Journal, 11(3): 243-263.

Ryan, R. M., \& Deci, E. L. 2000. Self-determination theory and the facilitation of intrinsic motivation, social development, and well-being. American Psychologist, 55(1): 68-78.

Scott, S. G., \& Bruce, R. A. 1994. Determinants of Innovative Behavior: A Path Model of Individual Innovation in the Workplace. The Academy of Management Journal, 37(3): 580-607.

Settoon, R. P., \& Mossholder, K. W. 2002. Relationship quality and relationship context as antecedents of person- and task-focused interpersonal citizenship behavior. Journal of Applied Psychology, 87(2): 255-267. 
Shalley, C. E., \& Perry-Smith, J. E. 2001. Effects of social-psychological factors on creative performance: The role of informational and controlling expected evaluation and modeling experience. Organizational Behavior and Human Decision Processes, 84(1): 1-22.

Shalley, C. E., Zhou, J., \& Oldham, G. R. 2004. The effects of personal and contextual characteristics on creativity: Where should we go from here? Journal of Management, 30(6): 933-958.

Shin, S. J., \& Zhou, J. 2003. Transformational leadership, conservation, and creativity: Evidence from Korea. Academy of Management Journal, 46(6): 703-714.

Simonton, D. K. 1984. Genius, Creativity, and Leadership: Histriometric Inquiries. Boston, MA: Harvard University Press

Singer, J. D. 1998. Using SAS PROC MIXED to fit multilevel models, hierarchical models, and individual growth models. Journal of Educational and Behavioral Statistics, 23(4): 323-355.

Stasser, G., Stewart, D. D., \& Wittenbaum, G. M. 1995. Expert roles and information exchange during discussion: The importance of knowing who knows what. Journal of Experimental Social Psychology, 31(3): 244-265.

Stasser, G., \& Titus, W. 1985. Pooling of unshared information in group decision making: Biased information sampling during discussion. Journal of Personality and Social Psychology, 48(6): 1467-1478.

Stasser, G., \& Titus, W. 1987. Effects of information load and percentage of shared information on the dissemination of unshared information during group discussion. Journal of Personality and Social Psychology, 53(1): 81-93.

Steele, C. M. 1975. Name-calling and compliance. Journal of Personality and Social Psychology, 31: 361-369. 
Sternberg, R. J. 1985. Implicit theories of intelligence, creativity, and wisdom. Journal of Personality and Social Psychology, 49(3): 607-627.

Stevens, M. J., \& Campion, M. A. 1994. The knowledge, skill, and ability requirements for teamwork: Implications for human resource management. Journal of Management, 20(2): 503-530.

Sutton, R. I., \& Hargadon, A. 1996. Brainstorming groups in context: Effectiveness in a product design firm. Administrative Science Quarterly, 41(4): 685-718.

Taggar, S. 2002. Individual creativity and group ability to utilize individual creative resources: A multilevel model. Academy of Management Journal, 45(2): 315-330.

Thibaut, J. W., \& Kelley, H. H. 1959. The social psychology of groups. Oxford, England: Wiley.

Tierney, P., Farmer, S. M., \& Graen, G. B. 1999. An examination of leadership and employee creativity: The relevance of traits and relationships. Personnel Psychology, 52(3): 591620.

VandeWalle, D., Ganesan, S., Challagalla, G. N., \& Brown, S. P. 2000. An integrated model of feedback-seeking behavior: Disposition, context, and cognition. Journal of Applied Psychology, 85(6): 996-1003.

Vogel, D., \& Wester, S. 2003. To seek help or not to seek help: The risks of self-disclosure. Journal of Counseling Psychology, 50(3): 351-361.

Wallas, G. 1926. The Art of Thought. New York: Harcourt, Brace.

Watson, P. C. 1960. On the failure to eliminate hypotheses in a conceptual task. Quarterly Journal of Experimental Psychology, 12: 129-140.

Weinstein, J., \& Morton, L. 2002. Stuck in a Rut: The Role of Creative Thinking in Problem Solving and Legal Education. Clinical L. Rev., 9: 835. 
Zhou, J. 2003. When the Presence of Creative Coworkers Is Related to Creativity: Role of Supervisor Close Monitoring, Developmental Feedback, and Creative Personality. Journal of Applied Psychology, 88(3): 413-422.

Zhou, J., \& George, J. M. 2001. When job dissatisfaction leads to creativity: Encouraging the expression of voice. Academy of Management Journal, 44(4): 682-696. 